http://dx.doi.org/10.35381/racji.v6i1.1425

\title{
Protección de niños inmigrantes en Ecuador
}

\section{Protection of immigrant children in Ecuador}

\author{
Juan Carlos Arandia-Zambrano \\ uq.juanarandia@uniandes.edu.ec \\ Universidad Regional Autónoma de los Andes, Quevedo \\ Ecuador \\ https://orcid.org/0000-0001-7301-5447 \\ Tanya Roxana Torres-Castillo \\ uq.tanyatorres@uniandes.edu.ec \\ Universidad Regional Autónoma de los Andes, Quevedo \\ Ecuador \\ https://orcid.org/0000-0001-8913-4352 \\ Nohely Sofía Valverde-Burgos \\ dq.nohelysvb04@uniandes.edu.ec \\ Universidad Regional Autónoma de los Andes, Quevedo \\ Ecuador \\ https://orcid.org/0000-0002-8293-3511
}

Recepción: 15 de marzo 2021

Revisado: 25 de mayo 2021

Aprobación: 15 de junio 2021

Publicación: 01 de Julio 2021 


\title{
RESUMEN
}

La Presente investigación desde el paradigma cuantitativo y el diseño bibliográficodocumental se apoyó en los procesos lógicos y mentales. El investigador organizó un proceso investigativo en donde la población de estudio, se basó primordialmente en documentos escritos como normas, leyes, estadísticas, para indagar los escritos con el objeto de estudiarlos. En este sentido el objetivo general del presente estudio fue realizar un análisis sobre las situaciones actuales de los niños inmigrantes en el ecuador sobre las vulneraciones de sus derechos. En la interpretación de la información recolectada, se puede determinar de la existencia de cierta forma en las que los niños, niñas y adolescentes pueden sufrir de manera directa o indirecta, situaciones riesgosas. Se concluye que es necesario salvaguardar a los migrantes y sobretodo hacer énfasis en garantizar y proteger los derechos de los niños en cada uno de los aspectos relacionados a protección de salud, educación, movilidad e integración.

Descriptores: Migración; inmigrante; infancia; derechos de los grupos especiales: bienestar de la infancia. (Palabras tomadas de Tesauro UNESCO).

\begin{abstract}
The present investigation from the quantitative paradigm and the bibliographicdocumentary design relied on logical and mental processes. The researcher organized an investigative process in which the study population relied primarily on written documents such as rules, laws, statistics, to investigate the writings in order to study them. In this sense, the general objective of this study was to carry out an analysis of the current situations of immigrant children in Ecuador regarding the violations of their rights. In the interpretation of the information collected, it can be determined the existence of a certain way in which children and adolescents can suffer, directly or indirectly, risky situations. It is concluded that it is necessary to safeguard migrants and, above all, to emphasize guaranteeing and protecting the rights of children in each of the aspects related to health protection, education, mobility and integration.
\end{abstract}

Descriptors: Migration; immigrant; childhood; rights of special groups: child welfare (words takenfrom UNESCO Thesaurus). 


\section{INTRODUCCIÓN}

En la actualidad existen en diferentes países situaciones que llevan a grupos de personas a salir de sus pueblos de origen para buscar mejores oportunidades en otros lugares, hay muchos escenarios por la que quieren abandonar su nación y trasladarse a otra, por ejemplo, esto puede ser causado por un conflicto armado o una crisis económica, por dictaduras y conflictos sociales, entre otros. Para Canelón Silva y Almansa Martínez (2018) destacan en la necesidad de tramitar las migraciones internacionales desde "un enfoque holístico que favorezca el tratamiento humano de los migrantes independientemente de su estatus migratorio, poniendo en primer plano la totalidad de sus dimensiones y aspectos esenciales como personas" (p. 118). Por otro lado, el Marco de la Gobernanza de la Migración de la Organización Internacional de las Migraciones (OIM, 2015, p.6) plantea tres objetivos específicos:

1. La buena gobernanza de la migración y las políticas conexas deberían fomentar el bienestar socioeconómico de los migrantes y de la sociedad.

2. La gobernanza adecuada de la migración se debería fundamentar en respuestas eficaces a la movilidad en situaciones de crisis.

3. La migración se debería efectuar de manera segura, ordenada y digna.

El fenómeno migratorio visible gracias a las nuevas tecnologías, puesto que antes el obtener información de ciertos temas era tarea muy complicada, por lo que podemos conocer más sobre lo que les sucede a las personas que disponen emigrar y sus dificultades desde el momento en que resuelven viajar hasta el instante en que puedan instalarse con éxito en el otro país, muy pocas veces es examinado en mayor profundidad al estado vulnerable que pueden llegar los individuos por la necesidad de buscar algo mejor, en la mayoría de casos no hay preparación adecuada ni los fondos necesarios para estos viajes pero a su vez esto se debe a la situación por la que ventilan marchar en primer lugar y por lo mismo desean irse a indagar otras oportunidades, es un círculo que los deja con escasas opciones, o se quedan y siguen pasando por necesidades o se van con todos los riesgos que implican y de la discriminación y rechazo que va a recibir. 
Mucha son las razones por las cuales se escoge el Ecuador como país por parte de los migrantes según Sánchez Bautista y Oviedo (2013, p.7) son las siguientes: Los flujos migratorios característicos del contexto de globalización; las políticas migratorias y la libre movilidad consignada en la Constitución de Montecristi; los conflictos internos de los países fronterizos; las dinámicas políticas, sociales y económicas de los países que recientemente se han convertido en puntos de origen de la migración internacional hacia Ecuador; y la dolarización han ayudado en su conjunto a incrementar la movilidad humana reciente hacia este país. Sin embargo, las personas que deciden partir a otras tierras se enfrentan a situación, que tienden a ser riesgosas durante los viajes y problemáticas cuando logran establecerse con sus familiares en otro país desde problemas sociales, educativos y financieros.

En síntesis, son personas las cuales deciden ir a otro país trasladarse en su mismo país de origen, quienes las situaciones riesgosas los han hecho tomar la decisión de dejar su lugar de origen para buscar nuevas oportunidades de sobrevivir en otro lado. La situación de los niños migrantes siempre ha sido un tema preocupante, especialmente en los últimos años, es posible mostrar un crecimiento sustancial en el país siendo el mayor número de personas de origen venezolano, las situaciones que pasan muchas de las familias al moverse de país a país es una cuestión problemática pero hay que sumarle que muchas de estas familias llevan a sus niños, niñas y adolescentes, las situaciones no solo empiezan al establecerse en otro país, si no que empiezan desde el momento en que empieza la movilización de país a país, ya que como bien sabemos no todos tienen los recursos para viajar "cómodamente" representando una situación peligrosa para el menor. 


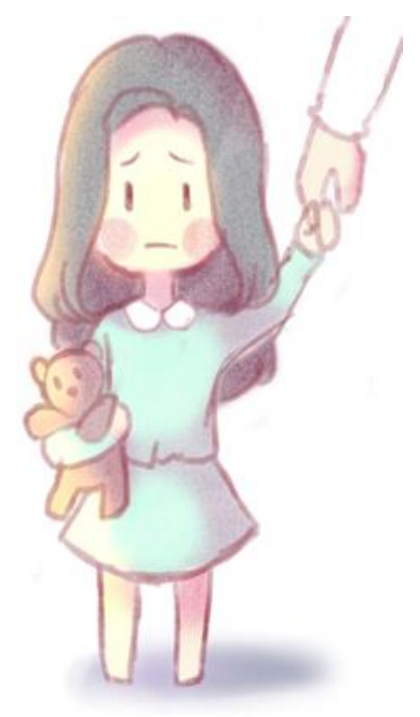

Figura 1. Rostro de un niño migrante Elaboración: Los autores.

De acuerdo a la UNICEF (2020) los niños y niñas migrantes son vulnerables a situaciones que pueden violentar sus derechos como:

- Ser detenidos

- Estar expuestos al crimen organizado o al tráfico de personas

- Sufrir violencia y discriminación

- Pasar hambre y frío

- No tener acceso a servicios de salud

Por su parte el Estado ecuatoriano mediante su legislación y acuerdo internaciones tiene la obligación de la protección de los niño y niñas que dejan sus lugares de origen por diferentes causas, en tal sentido se muestra el siguiente cuadro con las convenciones y normativa legal que apoya lo planteado anteriormente. 


\section{Cuadro 1.}

Protección de los niños y niñas.

\begin{tabular}{|c|c|c|}
\hline Estatuto & Artículo(s) & Disposición \\
\hline $\begin{array}{l}\text { Convención sobre los } \\
\text { Derechos del Niño(1989) }\end{array}$ & Articulo 3 & $\begin{array}{l}\text { Parágrafo } 1 \text { En todas las medidas } \\
\text { concernientes a los niños que tomen las } \\
\text { instituciones públicas o privadas de bienestar } \\
\text { social, los tribunales, las autoridades } \\
\text { administrativas o los órganos legislativos, una } \\
\text { consideración primordial a que se atenderá } \\
\text { será el interés superior del niño. } \\
\text { Parágrafo } 2 \text { Los Estados Partes se } \\
\text { comprometen a asegurar al niño la protección y } \\
\text { el cuidado que sean necesarios para su } \\
\text { bienestar, teniendo en cuenta los derechos y } \\
\text { deberes de sus padres, tutores u otras } \\
\text { personas responsables de él ante la ley y, con } \\
\text { ese fin, tomarán todas las medidas legislativas } \\
\text { y administrativas adecuadas. }\end{array}$ \\
\hline & Articulo 22 & $\begin{array}{l}\text { Parágrafo } 1 \text { Los Estados Partes adoptarán } \\
\text { medidas adecuadas para lograr que el niño que } \\
\text { trate de obtener el estatuto de refugiado o que } \\
\text { sea considerado refugiado de conformidad con } \\
\text { el derecho y los procedimientos internacionales } \\
\text { o internos aplicables reciba, tanto si está solo } \\
\text { como si está acompañado de sus padres o de } \\
\text { cualquier otra persona, la protección y la } \\
\text { asistencia humanitaria adecuadas para el } \\
\text { disfrute de los derechos pertinentes } \\
\text { enunciados en la presente Convención y en } \\
\text { otros instrumentos internacionales de derechos } \\
\text { humanos o de carácter humanitario en que } \\
\text { dichos Estados sean partes. } \\
\text { Parágrafo } 2 \text {. A tal efecto los Estados Partes } \\
\text { cooperarán, en la forma que estimen } \\
\text { apropiada, en todos los esfuerzos de las } \\
\text { Naciones Unidas y demás organizaciones } \\
\text { intergubernamentales competentes } \\
\text { organizaciones no gubernamentales que } \\
\text { cooperen con las Naciones Unidas por proteger } \\
\text { y ayudar a todo niño refugiado y localizar a sus } \\
\text { padres o a otros miembros de su familia, a fin } \\
\text { de obtener la información necesaria para que } \\
\text { se reúna con su familia. En los casos en que no } \\
\text { se pueda localizar a ninguno de los padres o } \\
\text { miembros de la familia, se concederá al niño la } \\
\text { misma protección que a cualquier otro niño } \\
\text { privado permanente o temporalmente de su } \\
\text { medio familiar, por cualquier motivo, como se } \\
\text { dispone en la presente Convención. }\end{array}$ \\
\hline
\end{tabular}




\begin{tabular}{|c|c|c|}
\hline & Artículo 27 & $\begin{array}{l}\text { Parágrafo } 1 \text { Los Estados Partes reconocen el } \\
\text { derecho de todo niño a un nivel de vida } \\
\text { adecuado para su desarrollo físico, mental, } \\
\text { espiritual, moral y social. }\end{array}$ \\
\hline \multirow[t]{2}{*}{$\begin{array}{l}\text { Código de la Niñez y } \\
\text { Adolescencia (2003) }\end{array}$} & Articulo 11 & $\begin{array}{l}\text { El interés superior del niño. El interés superior } \\
\text { del niño es un principio que está orientado a } \\
\text { satisfacer el ejercicio efectivo del conjunto de } \\
\text { los derechos de los niños, niñas y } \\
\text { adolescentes; e impone a todas las autoridades } \\
\text { administrativas y judiciales y a las instituciones } \\
\text { públicas y privadas, el deber de ajustar sus } \\
\text { decisiones y acciones para su cumplimiento. }\end{array}$ \\
\hline & Artículo 193 & $\begin{array}{l}\text { Políticas de Protección integral. Las políticas } \\
\text { de protección integral son el conjunto de } \\
\text { directrices de carácter público; dictadas por los } \\
\text { organismos competentes, cuyas acciones } \\
\text { conducen a asegurar la protección integral de } \\
\text { los derechos y garantías de la niñez y } \\
\text { adolescencia. El Sistema Nacional } \\
\text { Descentralizado de Protección Integral de la } \\
\text { Niñez y Adolescencia contempla cinco tipos de } \\
\text { políticas de protección integral. }\end{array}$ \\
\hline \multirow[t]{4}{*}{$\begin{array}{l}\text { Constitución de la } \\
\text { República del Ecuador } \\
\text { (2008) }\end{array}$} & Articulo 9 & $\begin{array}{l}\text { Las personas extranjeras que se encuentren en } \\
\text { el territorio ecuatoriano tendrán los mismos } \\
\text { derechos y deberes que las ecuatorianas, de } \\
\text { acuerdo con la Constitución. }\end{array}$ \\
\hline & Articulo 40 & $\begin{array}{l}\text { Se reconoce a las personas el derecho a } \\
\text { migrar. No se identificará ni se considerará a } \\
\text { ningún ser humano como ilegal por su } \\
\text { condición migratoria. }\end{array}$ \\
\hline & Articulo 41 & $\begin{array}{l}\text { Se reconocen los derechos de asilo y refugio, } \\
\text { de acuerdo con la ley y los instrumentos } \\
\text { internacionales de derechos humanos. Las } \\
\text { personas que se encuentren en condición de } \\
\text { asilo o refugio gozarán de protección especial } \\
\text { que garantice el pleno ejercicio de sus } \\
\text { derechos. El Estado respetará y garantizará el } \\
\text { principio de no devolución, además de la } \\
\text { asistencia humanitaria y jurídica de } \\
\text { emergencia. No se aplicará a las personas } \\
\text { solicitantes de asilo o refugio sanciones } \\
\text { penales por el hecho de su ingreso o de su } \\
\text { permanencia en situación de irregularidad. El } \\
\text { Estado, de manera excepcional y cuando las } \\
\text { circunstancias lo ameriten, reconocerá a un } \\
\text { colectivo el estatuto de refugiado, de acuerdo } \\
\text { con la ley. }\end{array}$ \\
\hline & Articulo 392 & $\begin{array}{l}\text { El Estado velará por los derechos de las } \\
\text { personas en movilidad humana y ejercerá la } \\
\text { rectoría de la política migratoria a través del } \\
\text { órgano competente en coordinación con los } \\
\text { distintos niveles de gobierno. El Estado } \\
\text { diseñará, adoptará, ejecutará y evaluará } \\
\text { políticas, planes, programas y proyectos, y } \\
\text { coordinará la acción de sus organismos con la }\end{array}$ \\
\hline
\end{tabular}




\begin{tabular}{|l|l|l|}
\hline & & $\begin{array}{l}\text { de otros Estados y organizaciones de la } \\
\text { sociedad civil que trabajen en movilidad } \\
\text { humana a nivel nacional e internacional. }\end{array}$ \\
\hline $\begin{array}{l}\text { Declaración Universal de } \\
\text { los Derechos Humanos } \\
(1948)\end{array}$ & Articulo 2 & $\begin{array}{l}\text { Toda persona tiene todos los derechos y } \\
\text { libertades proclamados en esta Declaración, } \\
\text { sin distinción alguna de raza, color, sexo, } \\
\text { idioma, religión, opinión política o de cualquier } \\
\text { otra índole, origen nacional o social, posición } \\
\text { económica, nacimiento o cualquier otra } \\
\text { condición. }\end{array}$ \\
\hline Articulo 7 7 & $\begin{array}{l}\text { Todos son iguales ante la ley y tienen, sin } \\
\text { distinción, derecho a igual protección de la ley. } \\
\text { Todos tienen derecho a igual protección contra } \\
\text { toda discriminación que infrinja esta } \\
\text { Declaración y contra toda provocación a tal } \\
\text { discriminación. }\end{array}$ \\
\hline Articulo 13 \\
$\begin{array}{l}\text { Parágrafo 1. Toda persona tiene derecho a } \\
\text { circular libremente y a elegir su residencia en el } \\
\text { territorio de un Estado. } \\
\text { Parágrafo 2. Toda persona tiene derecho a salir } \\
\text { de cualquier país, incluso del propio, y a } \\
\text { regresar a su país. }\end{array}$ \\
\hline
\end{tabular}

Elaboración: Los autores.

De acuerdo a las normas citadas se observa que existen los fundamentos legales para la protección de los niños inmigrantes en el Ecuador, como garantía de sus derechos fundamentales lo que les permite obtener algunos beneficios para su desarrollo integral.

En este sentido el objetivo general del presente estudio es realizar un análisis sobre las situaciones actuales de los niños inmigrantes en el ecuador sobre las vulneraciones de derechos.

\section{METODOLOGÍA}

Desde el paradigma cuantitativo, se manejó para este tipo de estudio, documentos, textos legales, investigaciones científicas mediante la recolección, selección y análisis de los mismo. El diseño bibliográfico-documental se apoyó en los procesos lógicos y mentales. El investigador organizó un proceso investigativo en donde la población de estudio, se basó primordialmente en documentos escritos como normas, leyes, estadísticas, para indagar los escritos con el objeto de estudiarlos y construir conclusiones que favorecen en la generación de nuevos conocimientos. Las técnicas de interpretación de la indagación, se consideró el análisis de contenido de la 
información recopilada, lo que permitió la formulación de resultados. Así lo analíticosintético, consistió en descomponer mentalmente el sistema estudiado en varios elementos para poder llegar a la obtención de nuevos conocimientos del tema investigado.

\section{RESULTADOS}

Situación general de los niños migrantes:

Se puede identificar que en las situaciones de migración en donde hay menores de edad, la mayoría sufren los mismos problemas ya sea en menor o mayor medida, según la información proporcionada por la UNICEF (2020, p.6) en un informe, "Los niños, niñas y adolescentes en movilidad humana a menudo son víctimas de discriminación, xenofobia y estigma, durante sus viajes y en sus destinos finales." De acuerdo al informe desarraollado por esta organización y a través del levantamiento mediante encuestas a familias con niños, niñas y adolescentes en movilidad humana en Rumichaca (Carchi) y San Miguel (Sucumbíos). Si bien los datos reflejan los resultados de aproximadamente 4,400 encuestas, los resultados no son extrapolables a toda la población en movilidad. Los resultados fueron los siguientes: El 98\% no tenían suficiente dinero para llegar a su destino. El 43,7\% reporto no haber tenido acceso a agua segura en su viaje. El 43, 7\% reporto no tener acceso a educación formal en el Ecuador.

Aquí están limitadas situaciones relacionadas al derecho al agua y educación, pero falta denotar las situaciones relacionadas a la xenofobia y a la salud. Las condiciones más comunes que pasan algunos de los migrantes desde un inicio, son las situaciones en que pueden contraer diarrea, enfermedades respiratorias, no tener suficientes comida, no tener acceso a agua limpia para consumir; que se los envíen devuelta a su país, que les roben en el camino, que tengan problemas con sus documentos, que exista la situación de que los niños se separen de los padres, que el dinero no es suficiente como para llegar a su destino o que no pueden estudiar por algún motivo. 


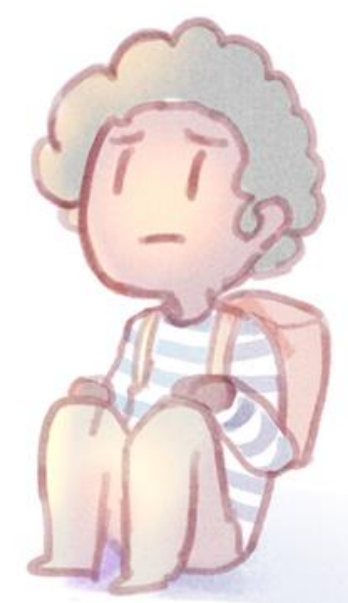

Figura 2. Sufrimientos de los niños ante estas situaciones de movilidad. Elaboración: Los autores.

El Ecuador se rige a ciertos compromisos para proteger a los niños, niñas y adolescentes en casos de movilidad humana, la primera es que se sitúan a los niños como prioridad absoluta por sobre toda política migratoria, lo que quiere decir el interés superior del niño y protección prevalece ante todo y es la prioridad máxima para el estado; el derecho a la vida familiar y la reunificación se refiere a que quiere evitar la separación de familias y en ese caso intentar que se reúnan lo más pronto posible y por ultimo e la no discriminación, que sin importar la raza, creencias, estatus entre otros.

Niños migrantes y el derecho a la salud:

Es conocido por todos que el derecho a la salud es un derecho fundamental, el cual la ley establece que debe ser garantizado por el mismo Estado especialmente si lo enfocamos a los menores de edad, el gobierno debe enfocarse en crear medidas 0 planes para ayudar, ahora en el contexto de movilidad y basados en un estudio realizado por $\operatorname{UNICEF(2018)}$ los resultados arrogaron que las situaciones más comunes que afectan a la salud de los niños son la diarrea, enfermedades respiratorias, falta de alimentos, falta de servicios de higiene y falta de agua segura para beber, en cuanto a lo que corresponde a la salud, no es difícil pensar que durante los viajes de país a país que deben realizar los menores puedan sufrir algunos de estos problemas, enfermedades como la diarrea o cosas peores como una 
desnutrición o anemia los cuales se especifican del Estado como una garantía; pero sin embargo aunque es un estudio centrado en niños migrantes son situaciones que siguen ocurriendo y que les puede pasar a cualquier otro niño de cualquier nacionalidad.

Niños inmigrantes y la discriminación:

Otro punto de importante de la presente investigación es la discriminación es una de las principales razones por las que suelen suceder estas situaciones, es pensar que todos los que son latinoamericanos son alegres, divertidos y fiesteros, siendo parte de Latinoamérica es fácil darse cuenta de que esta afirmación es falsa porque todos no son así, y si se plantea lo mismo con algún estereotipo de otro país en específico es fácil observa de que es solo una generalización y no generalizar al $100 \%$ a todos sus habitantes, entonces ¿porque siguen existiendo estas situaciones de xenofobia contra extranjeros?. Una definición que ciertamente se encuentra acertada es la de (Lara Salinas, 2007,p.213) que expone: "La xenofobia, el fastidio u odio contra los inmigrantes, contra el diferente, contra el que no es como uno, es una consecuencia de imágenes prejuiciosas que hacen ver al inmigrante como la causa de los males de la sociedad." Entonces siguiendo este modelo de pensamiento es inevitable el no incluir el etnocentrismo, el cual dificulta la comprensión de las demás culturas, por lo que se podría decir que es una visión centrada en la realidad misma de una persona que considera a su país y cultura razona que no es superior, pero si mejor en cierta medida y dejando a las demás culturas o nacionalidades es una posición inferior.

En un artículo realizado por (Moreno Calderón y Silva Quintero, 2019) se mencionan a los medios de comunicación los cuales tienen un papel importante en la percepción de la opinión pública. Concordando con esta afirmación, los medios de comunicación ayudan en cierta medida a crear una visión de una realidad al comunicar hechos, dependiendo de cómo presenten la información y de que medio se transmita la información, pero lo mismo deben de ser imparciales al comunicar las mismas, aunque no podemos estar realmente seguros del verdadero impacto.

Las situaciones de xenofobia son a veces difíciles de enfrentar en un adulto peor aún si es un niño, las situaciones como estas suelen ocurrir en escuelas, como el hecho 
de que los demás no quieran interactuar con él, le excluyan de actividades, que le digan cosas hirientes por el hecho de ser de otro país, o que se burlen si tiene algún tipo de acento, para corroborar estas situaciones se puede evidenciar desde los últimos años la cantidad de noticias de diferentes medios del cómo se denuncian estas situaciones como el que sean insultados de la nada, agredidos, o hasta el punto de que les quieran negar derechos que son una garantía del Estado ecuatoriano, o que a los adultos migrantes se les niegue el trabajar en algún lugar por su condición de migrante, si resulta que esta persona tiene algún menor de edad a cargo indirectamente también afecta, todo lo que pasa de alguna u otra forma termina afectando a los niños física o psicológicamente.

\section{DISCUSIÓN}

En interpretación de la información recolectada, se puede determinar de la existencia de ciertas forma en las que los niños, niñas y adolescentes pueden sufrir de manera directa o indirecta, durante la migración en donde experimentan situaciones riesgosas, a lo que puede darse como respuesta el que, no todos realizan los viajes con las mismas condiciones y no todos tienen la misma experiencia al mudarse a otro país, otro cuestionamiento relevante es pensar que si aún hoy en día pasan estas situaciones agregando el hecho de que a fechas de la realización de este estudio estamos en una emergencia sanitaria, la respuesta que se puede plantear es que a pesar de que el número de migrantes haya podido aumentar según predicciones de la ONU y que existan planes de ayuda a extranjeros, eso no inhibe el hecho de que algunas familias que junto a sus niños viajen y se encuentren con este tipo de dificultades, además hay que sumarle el hecho de que aunque existan campañas 0 concientización de que todos los migrantes no son malos aún existen personas que van a discriminar y expresaran su xenofobia hacia los mismo; otra de ellas es que hay personas que duermen a la intemperie muchas de ellas con niños; o personas que piden caridad en calle o van de casa en casa, es decir que estas situaciones de vulneración siguen y seguirán existiendo. 


\section{CONCLUSIONES}

Al concluir la investigación se puede indicar que uno de los derechos más vulnerados y que perjudican a los niños, niñas y adolescentes en situación de migración son los relacionados a la salud, educación, la no discriminación y el derecho a la protección han sido los más nombrados y tristemente los más comunes por los cuales algunos niños sufren en su trayecto junto a sus familias para buscar una nueva oportunidad en otro país.

Otro aspecto a considerar, es que el estudio se enfocó en una vista más "general" es obvio el recalcar que la mayoría de afluencia de migrantes son los de Venezuela, aunque existen también migrantes de otras nacionalidades que salen de sus países por diversos motivos, los venezolanos son el grupo más grande en los últimos años y a su vez son los que reciben más discriminación por el hecho de ser otro país.

Para finalizar, se destaca la existencia de varios códigos y convenios en Ecuador, su Constitución, el Código de la Niñez y Adolescencia, la Convención de los Derechos del Niño, la Declaración Universal De Derechos Humanos, las cuales en su contenido exponen la importancia de proteger y salvaguardar a los migrantes y sobretodo hacen énfasis en garantizar y proteger los derechos de los niños en cada uno de los aspectos relacionados a salud, educación, movilidad e integración, pero aun así existen situaciones que vulneran dichas normas; aunque los derechos sean garantizados en la vida real la situación es otra y se reflejan los mismos en varias noticias, seguirán existiendo hasta que las medidas para ayudar a los menores y sus familias sean más eficaces y eficientes de lo que ya son.

\section{FINANCIAMIENTO}

No monetario.

\section{AGRADECIMIENTO}

A la Universidad Regional Autónoma de los Andes, Ecuador; por motivar el desarrollo de la Investigación. 


\section{REFERENCIAS CONSULTADAS}

Asamblea Nacional Constituyente de la República del Ecuador, (2008). Constitución de la República del Ecuador. [Montecristi. Registro Oficial 449 de 20-oct-2008. Recuperado de https://n9.cl/sia

Canelón Silva, A. y Almansa Martinez, A. (2018). Migración: retos y oportunidades desde la perspectiva de los Objetivos de Desarrollo Sostenible (ODS). [Migration: challenges and opportunities from the perspective of the Sustainable Development Goals (SDGs)]. Retos Revista de Ciencias de La Administración y Economía, 8(16), 109-120. https://doi.org/https://doi.org/10.17163/ret.n16.2018.08

Congreso Nacional. (2003). Código de la niñez y adolescencia. [Childhood and Adolescence Code]. Quito.

Lara Salinas, A. (2007). Migraciones internacionales, seguridad y xenofobia: los límites del modelo francés de integración. [International migration, security and xenophobia: the limits of the French integration model]. OASIS, (12), 209-227. Recuperado a partir de: https://n9.cl/n14cj

Moreno Calderón, V, y Silva Quintero, J. (2019). Venezuela crisis humanitaria y recepción de migrantes en Colombia: creciente xenofobia ante los migrantes venezolanos. [Venezuela humanitarian crisis and reception of migrants in Colombia: growing xenophobia towards Venezuelan migrants]. Recuperado de: https://n9.cl/etbij

OIM. (2015). Marco de la Gobernanza de la Migración. [ Migration Governance Framework]. Ginebra. Recuperado de: https://bit.ly/2RVy008

Organización de las Naciones Unidas (1948). La Declaración Universal de Derechos Humanos [The Universal Declaration of Human Rights]. Recuperado de https://n9.cl/xe66

Organización de Naciones Unidas. (1989). Convención sobre los derechos del Niño. Interés superior del niño. [Convention on the Rights of the Child. Best interest of the child.] Invention on the rights of the Child. Child's best interest] San Francisco, Estados Unidos: ONU.

Sánchez Bautista, C., y Oviedo, S. (2013). Los niños, niñas y adolescentes inmigrantes en Ecuador: avances y deudas en el cumplimiento de sus derechos. - 1a ed. - Ciudad Autónoma de Buenos Aires: CLACSO. Recuperado de: https://n9.cl/ua5xja 
UNICEF (2020) Migración de niñas, niños y adolescentes Los derechos de niñas, niños y adolescentes migrantes viajan con ellos y deben ser respetados. [Migration of children and adolescents The rights of migrant children and adolescents travel with them and must be respected]. Recuperado de: https://n9.cl//bk5g5

UNICEF. (2018). Niñez venezolana en contexto de movilidad humana Euador. [Venezuelan children in the context of human mobility Euador]. Recuperado de: https://n9.cl/moncb 